\title{
Antibiotic Sales in Primary Care in Hubei Province, China: An Analysis of 2012-2017 Procurement Records
}

\author{
Xinping Zhang ${ }^{1}$, Youwen Cui ${ }^{1}{ }^{\circledR}$, Chaojie Liu ${ }^{2}{ }^{\circledR}$, Keyuan $_{\text {Zuo }}{ }^{3}$ and Yuqing Tang ${ }^{1, *}$ \\ 1 School of Medicine and Health Management, Tongji Medical College, Huazhong University of Science \\ and Technology, Wuhan 430030, China \\ 2 School of Psychology and Public Health, La Trobe University, Melbourne, VIC 3086, Australia \\ 3 Department of Pharmaceuticals Bidding and Procurement, Hubei Public Resource Trading Center, \\ Wuhan 430030, China \\ * Correspondence: dr_tyq@163.com
}

Received: 1 July 2019; Accepted: 7 September 2019; Published: 12 September 2019

\begin{abstract}
The over-use of antibiotics has been identified as a major global challenge, where there is insufficient knowledge about the use of antibiotics in primary healthcare settings, especially at a population level. This study aims to investigate the trends and patterns of antibiotic sales in primary care in Hubei, China over a six-year period from 2012 to 2017. Antibiotic sales were expressed with Defined Daily Doses per 1000 inhabitants per day (DIDs) and compared with European countries using the 12 quality indicators proposed by the scientific advisory board of the European Surveillance of Antimicrobial Consumption (ESAC) project. Antibiotic sales increased from 12.8 DID in 2012 to 15.3 DID in 2013, and then declined afterwards. The most commonly used antibiotics, J01C (beta-lactam antimicrobials, penicillins), accounted for $40.5 \%$ of total antibiotic sales. Parenteral administration of antibiotics accounted for over $50 \%$ of total antibiotic sales. Total antibiotic sales were almost on a par with the 31 European countries monitored by the ESAC project, but cephalosporin sales were higher than at least three quarters of the compared countries, resulting in a significant higher proportion of third-generation cephalosporin consumption (13.8-19.43\%). The relative consumption of Fluoroquinolone $(9.26-9.89 \%)$ was also higher than at least half of the compared countries. There is a lack of robust evidence to show that antibiotic consumption in primary care is lower in Hubei compared with other countries. The preference of clinicians in China to use broad-spectrum and parenteral antibiotics deserves further study and policy attention.
\end{abstract}

Keywords: primary care; antibiotic sales; China; quality indicators

\section{Introduction}

The over-use of antibiotics has been identified as a major global challenge, especially in low- and middle-income countries (LMIC) [1,2]. It has been proved to be associated with the development and spread of antimicrobial resistance (AMR), an alarming global public health threat. Deaths attributed to drug-resistant infections may surpass 10 million in 2050, and could result in an estimated \$US100 trillion loss in global economic output if the rising trend is not properly contained from the current level of 700,000 deaths annually [3]. There is also an urgent global need to find new antibiotics [4].

Global consumption of antibiotics increased by 39\% between 2000 and 2015 [5], with the majority being dispensed from primary care facilities [6]. Irrational antibiotic prescriptions are most prevalent in the primary care sector [7,8]. China is no exception [9]. The primary care network in China, including community/township health centres and their outreach stations/clinics [10], provided $54.2 \%$ of outpatient care ( 4.43 billion visits) and $18.2 \%$ of inpatient care ( 44.5 million hospital admissions) 
in 2017 [11]. The over-prescription of antibiotics is common in these facilities [12]. In Shandong, for example, primary care institutions dispensed about $80 \%$ of all antibiotics for medical care. Previous studies have proven that the irrational use of antibiotics in primary care, especially for longer and more frequent antibiotic courses, contributes to the asymptomatic carriage of resistant bacteria, which can last for up to 12 months [13-16].

Efforts in many countries to contain antibiotic consumption in primary care have failed [17]. In China, it is widely believed that the over-prescription of medicines, including antibiotics, has its roots in the distorted pricing system introduced over the period when China transitioned from a planned economy to a market one in the 1980s. Inadequate government funding, fee for-service payments, and the $15 \%$ profit margin on the sales of medicines incentivised over-prescription. Antibiotics became one of the most commonly abused pharmaceutical products $[18,19]$. Despite policy interventions imposing a cap on the sales of medicines as a percentage of total revenue, over-prescription was still deemed a big problem [20-22]. It was estimated that the sales of medicines accounted for $44.0 \%$ of hospital revenue and 59.1\% of primary care revenue, respectively, in 2008 [23].

Attempting to further curtail irrational prescriptions in primary care, the Chinese government launched a round of comprehensive system reforms in 2009. Prescriptions in primary care were restricted to those included on the essential medicines list (EML). A profit margin for the sales of medicines was disallowed. A regional government tendering platform was set up to procure essential medicines for primary care facilities [24]. Empirical data showed limited evidence of the policy impact on antibiotic prescribing practices, despite a drop in the price of essential medicines [25-27].

In 2012, the Chinese government issued new "administrative rules for the clinical use of antibiotics". This is considered the most rigid regulatory control over antibiotic prescriptions to date [28,29]. Antibiotics were categorised into three groups: Non-restricted, restricted and controlled; and controlled antibiotics were excluded from the EML for primary care. Prescriptions of restricted (or controlled) antibiotics were subject to strict administrative restrictions. Penalties are applied for violating the rules [30].

Little is known of the effects of the 2012 policy. This study aimed to investigate the trends and patterns of antibiotic sales in primary care in Hubei over a six-year period from 2012 to 2017, in comparison with the European Surveillance of Antimicrobial Consumption (ESAC) results [31].

\section{Materials and Methods}

This study analysed the aggregated data of antibiotic procurement for all public primary care facilities in Hubei, China over the period from 2012 to 2017. Approximately $60 \%$ of outpatient visits in 2017 in Hubei province were in primary care facilities (Table 1). Public primary care institutions in Hubei share approximately $75 \%$ of patient visits to all primary care facilities [32]. The public primary care facilities thus shared approximately $45 \%$ (60\% multiplied by $75 \%)$ of total outpatient visits in Hubei province in 2017.

Table 1. Outpatient visit data for primary care and hospital sector in Hubei province, 2012-2017.

\begin{tabular}{ccccc}
\hline Year & Year-End Population (10,000) & Primary Care Visit & Hospital Sector Visit & Share (\%) of Primary Care \\
\hline 2012 & 5799 & $194,226,467$ & $92,367,048$ & 67.77 \\
2013 & 5799 & $221,885,235$ & $98,597,112$ & 69.23 \\
2014 & 5816 & $239,407,480$ & $109,767,232$ & 68.56 \\
2015 & 5851.5 & $205,444,029$ & $117,219,783$ & 63.67 \\
2016 & 5885 & $212,090,000$ & $126,660,279$ & 62.61 \\
2017 & 5902 & $205,080,000$ & $135,382,043$ & 60.24 \\
\hline
\end{tabular}

\subsection{Study Setting}

Hubei province is located in central China, with a population of over 59 million (in 2017) across a geographic area of $185,900 \mathrm{~km}^{2}$. The annual average income per capita in Hubei ranks in the middle range of all provinces. In 2016, urban residents in Hubei had an average annual income of 12,725 Yuan 
(US\$1916) per person compared with 12,363 Yuan (US\$1861) across the country, while rural residents had an average annual income of 29,386 Yuan (US\$4424) per person compared with 33,616 Yuan (US\$5061) across the country [33]. About $5.89 \%$ of the gross domestic product (GDP) in Hubei was spent on health. In 2017, Hubei had 2.50 physicians, 3.12 nurses, and 6.37 beds per 1000 residents in the health care sector [34].

Hubei started to introduce the essential medicines system in 2010. Universal coverage was achieved the next year. In line with the national strategy, the "administrative rules for the clinical use of antibiotics" has been implemented since August 2012. In the "management measures for the clinical use of essential medicines" issued in November 2014, the Hubei government set a clear target to bring antibiotic prescriptions in primary health care settings down to no more than $20 \%$ for outpatient prescriptions and $40 \%$ for prescriptions in emergency care, respectively. The clinical use of antibiotics was capped at 40 defined daily doses (DDD) per hundred patient days [35].

\subsection{Data Source}

Data for this study were extracted from the Hubei Medical Procurement Administrative System (HMPAS). The HMPAS is the only online platform run by the government to procure pharmaceutical products for public facilities in Hubei. It was introduced in 2011 for public-owned primary care facilities.

Public primary care institutions can only order medicines from the HMPAS on a monthly basis. The system records the volume and expense of each type of medicine purchased by each facility. The procured medicines are categorised using the anatomical therapeutic chemical (ATC) classification codes. Records of "J01" (antibacterial for systemic use) procurement for primary care facilities from 2012 to 2017 were extracted for the purpose of this study.

\subsection{Data Analysis}

Antibiotic sales were measured using the DDD method developed by the World Health Organisation (WHO) [36]. DDD indicates the average maintenance dose per day for a drug used for its main indication in adults. According to the WHO Collaborative Centre for Drug Statistics Methodology, DDD equivalence per package (DPP) of medicines was calculated using the formula: $\mathrm{DPP}=$ (unit strength $\times$ pack size/DDD). The total volume of procurement was estimated as the summed DDDs of all packaged products.

$$
D D D s=\sum_{i=1}^{n}\left(D P P_{i} \times N_{i}\right)
$$

where $N_{i}$ represents the number of packages of certain product (i).

We calculated the DDDs for systemic antibiotics (J01) and its subsequent subgroups such as (J01C) penicillin and (J01D) cephalosporin (a full list of subgroups can be found in Table 2). The DDDs were then transformed into DDDs per 1000 inhabitants per day (DIDs) in order to determine the antibiotic sales trends over the years. The number of inhabitants was denoted as end-of-the-year population size in the annual statistical reports. Since $25 \%$ of patient visits to primary care facilities are not covered by the public primary care institutions, we reduced the denominator (end of the year population size) by $25 \%$ with the assumption that the majority of patients visiting private institutions generally do not go to public institutions and consultation rates would be similar in both groups. 
Table 2. Sales of various categories of antibiotics in primary care in Hubei China (2012-2017).

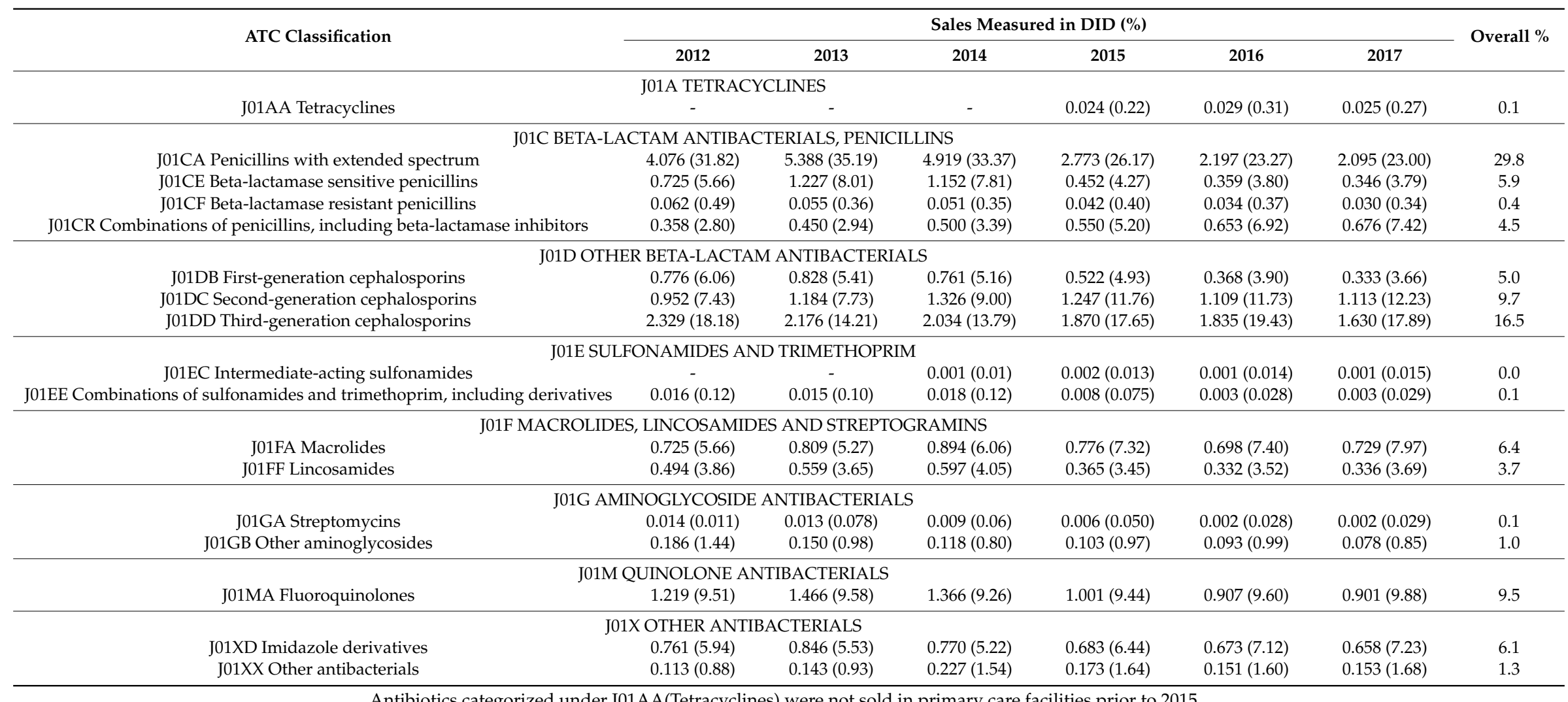

Antibiotics categorized under J01AA(Tetracyclines) were not sold in primary care facilities prior to 2015. 
The 12 quality indicators measuring antibiotic use in primary care proposed by the scientific advisory board of the European Surveillance of Antimicrobial Consumption (ESAC) project were adopted to assess the potential irrational use of antibiotics [31]. The 12 quality indicators cover DIDs of J01 and its four subgroups J01C (beta-lactam antimicrobials, penicillins), J01D (other beta-lactam antimicrobials), J01F (macrolides, lincosamides and streptogramins) and J01M (quinolone antibacterial), as well as the percentages of J01CE (beta-lactamase sensitive penicillins), J01CR (combinations of penicillins, incl. beta-lactamase inhibitors), J01DD (third-generation cephalosporins) + DE (fourth-generation cephalosporins), and J01MA (fluoroquinolones) in total antibiotic (J01) sales. The pattern of antibiotic sales was also measured by the ratio of broad and narrow spectrum antibiotics and seasonal variations of J01 and J01M sales. The ESAC published the performance of 31 European countries on the 12 quality indicators from 2012 to 2017 for benchmarking [37]. In the benchmarking analysis, we adjusted the absolute antibiotic sales figures in line with the market share of public primary care facilities in outpatient visits in Hubei province in 2017 ( $45 \%$ in Hubei province). The estimated outpatient antibiotics sales were then compared with 31 European countries in the corresponding year from 2012 to 2017. This is not perfect, as in European countries some small proportion of outpatients are seen in the hospital, while our adjustment assumes this is zero.

\section{Results}

On average, antibiotic sales in primary care in Hubei increased from 12.8 DID in 2012 to 15.3 DID in 2013, and then declined afterwards. The year of 2015 experienced the sharpest drop, down from 14.8 DID to 10.5 DID. This was followed by a slight further decline to 9.5 DID in 2016 and 9.1 DID in 2017. Such a trend was mainly shaped by changes in penicillin sales. The decrease in the sales of other antibiotic products was much less dramatic (Figure 1).

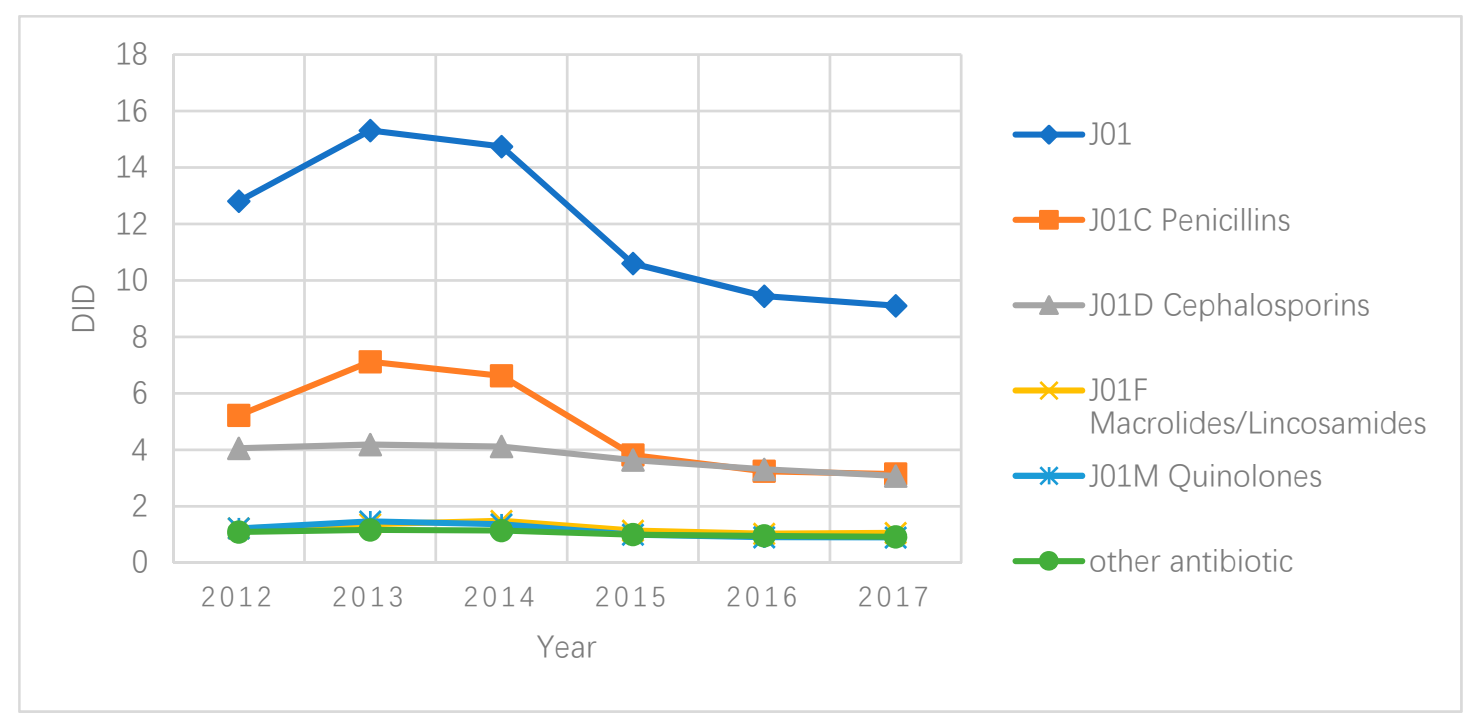

Figure 1. Antibiotic sales (DID) in primary care settings in Hubei, China, 2012-2017.

The most commonly used antibiotics were J01C (beta-lactam antimicrobials, penicillins), accounting for $40.5 \%$ (ranging from $34.3 \%$ to $46.5 \%$ over the years) of total antibiotic sales, followed by J01D (other beta-lactam antimicrobials; 31.1\%), J01F (macrolides, lincosamides and streptogramins; 10.2\%) and J01M (quinolone antibacterial; 9.5\%). But since 2015, the sales of cephalosporins have been on par with that of penicillins.

The percentage of parenteral administration of antibiotics experienced a slight increase over the years, up from about $50 \%$ to over $55 \%$ (Figure 2). 


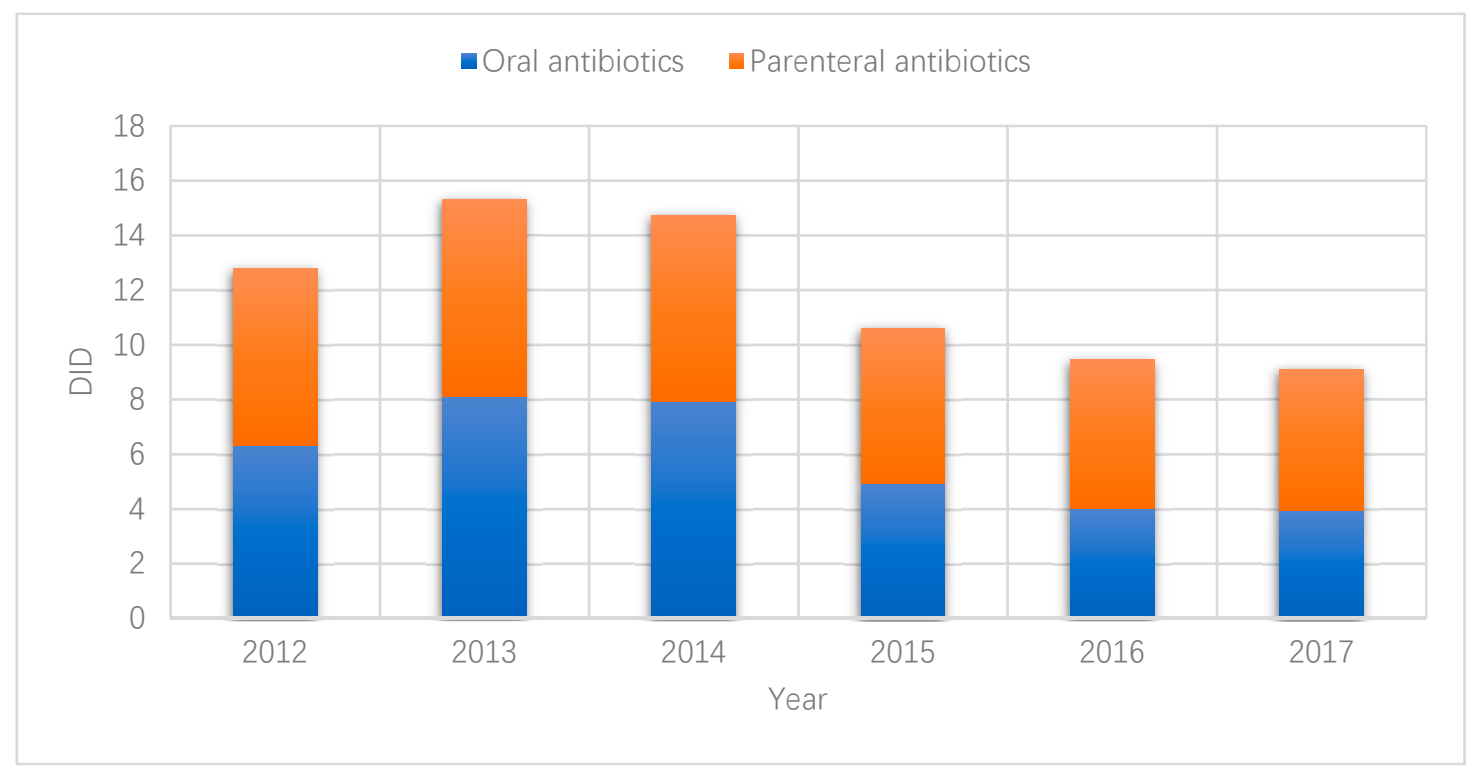

Figure 2. Sales of oral and parenteral antibiotics in primary care settings in Hubei, China, 2012-2017.

Extended-spectrum penicillins (J01CA) dominated the sales of penicillins, accounting for $73.5 \%$ of the total antibiotic sales (ranging from $66.6 \%$ to $78.1 \%$ over the years). Although the sales of both extended-spectrum (from the peak of 5.388 DID in 2013 to 2.095 DID in 2017) and narrow-spectrum penicillins (from 1.281DID in 2013 to 0.376 DID in 2017) dropped, the use of combinations of penicillins increased steadily from 0.358 DID in 2012 to 0.676 DID in 2017 (Table 2).

The sales of first, second and third generations of cephalosporin contributed to $16.0 \%$ (ranging from $10.84 \%$ to $19.77 \%$ over the years), $31.1 \%$ (ranging from $23.46 \%$ to $36.19 \%$ over the years) and $53.0 \%$ (ranging from $49.34 \%$ to $57.41 \%$ over the years) of the total sales of cephalosporin (J01D). Overall, cephalosporin sales declined over the years across all of the three generations (Table 2).

Fluoroquinolone (J01MA) was the only quinolone product used in primary care in Hubei. Its sales have decreased steadily over the years. Macrolides and lincosamides accounted for $63.3 \%$ and $36.7 \%$ of the total J01F (macrolides, lincosamides and streptogramins) sales, respectively. Aminoglycoside antibacterials, sulfonamides and trimethoprim and imidazole derivatives accounted for $1.1 \%, 0.1 \%$ and $6.1 \%$ of the total antibiotic sales, respectively. Similarly, their sales also declined over the years.

Overall, estimated outpatient antibiotic sales in Hubei were almost on a par with the 31 European countries monitored by the ESAC project (Table 3). Penicillin (J01C) sales were low after 2016, not only in absolute terms (DID) but also in relative terms as a percentage of total antibiotic sales. The sales of J01F (macrolides, lincosamides and streptogramins) and J01M (quinolone antibacterial) were in the low/middle or high range of the compared countries. But cephalosporin (J01D) sales were higher than at least three quarters of the compared countries, resulting in a significant higher proportion of J01DD (third-generation cephalosporin) sales (13.8-19.43\%) compared with the 31 European countries (8.4-8.9\%). The relative sales of J01MA (Fluoroquinolone, 9.26-9.89\%) and J01CE (beta-lactamase sensitive penicillins, $3.8-3.72 \%$ ) as a percentage of total antibiotic sales were also higher than at least half of the compared countries. The ratio of broad/narrow spectrum antibiotics increased over the years, but still fell into the lower end of the compared countries. Seasonal variations in both total antibiotic and quinolone sales were lower than most of the compared countries (Table 3). 
Table 3. Quality indicators for antibiotic sales in outpatient in Hubei in comparison with 31 European countries (highlighted in different colours).

\begin{tabular}{|c|c|c|c|c|c|c|c|c|c|c|c|c|}
\hline \multirow{2}{*}{ Year } & \multicolumn{5}{|c|}{ Absolute Sales * } & \multicolumn{4}{|c|}{ Relative Sales } & \multirow{2}{*}{$\begin{array}{c}\text { Broad/Narrow } \\
\text { J01_B/N }\end{array}$} & \multicolumn{2}{|c|}{ Seasonal Variations } \\
\hline & J01_DID & J01C_DID & J01D_DID & J01F_DID & J01M_DID & J01CE_\% & J01CR_\% & J01DD+DE_\% & J01MA_\% & & J01_SV & J01M_SV \\
\hline 2012 & 21.34 & 8.70 & 6.76 & 2.03 & 2.03 & 5.66 & 2.8 & 18.19 & 9.52 & 2.98 & 6.01 & 1.15 \\
\hline 2013 & 25.51 & 11.87 & 6.98 & 2.28 & 2.44 & 8.02 & 2.94 & 14.21 & 9.58 & 2.37 & 12.27 & 10.78 \\
\hline 2014 & 24.57 & 11.04 & 6.87 & 2.48 & 2.28 & 7.82 & 3.39 & 13.8 & 9.26 & 2.63 & 14.39 & 17.24 \\
\hline 2015 & 17.67 & 6.36 & 6.07 & 1.90 & 1.67 & 4.27 & 5.19 & 17.65 & 9.44 & 4.52 & 11.97 & -15.22 \\
\hline 2016 & 15.74 & 5.41 & 5.52 & 1.72 & 1.51 & 3.8 & 6.91 & 19.43 & 9.6 & 5.78 & 7.45 & -0.88 \\
\hline 2017 & 15.18 & 5.24 & 5.13 & 1.77 & 1.50 & 3.8 & 7.42 & 17.9 & 9.89 & 5.99 & N/A & N/A \\
\hline
\end{tabular}

* Adjusted with the market share (45\%) of primary care facilities in outpatient visits; Higher than all of the compared countries;

Ranked in the middle $25 \%$ of countries above median; Ranked in the middle $25 \%$ of countries below median; Ranked in bottom $25 \%$ of compared countries; $\quad$ Lower than all of the compared countries. 


\section{Discussion}

To the best of our knowledge, this is the first study of its kind to estimate population-wide antibiotic use in primary care in central China, using the widely accepted quality indicators (QIs) proposed by the ESAC project. Through a benchmarking analysis, we revealed some patterns of antibiotic use in primary care that were unknown to previous studies.

The total antibiotic sales in public primary care facilities in Hubei as expressed by DID are similar or even lower compared with those reported by the ESAC study countries. This is unexpected since previous studies illustrated a prescribing pattern in China characterised by the over-prescription of antibiotics. This finding should be interpreted with caution. Public primary care facilities share about $45 \%$ of the total volume of outpatient visits in Hubei, much lower in comparison with the European countries. In most European countries, more than $80 \%$ of outpatient encounters occur in primary care facilities [38]. In the absence of a "gate-keeping" role of primary care services, patients enjoy the freedom to choose hospitals as their preferred first contacts. Empirical evidence shows that consumer demands for non-referred outpatient services in hospitals have always been high in China [39]. There is a great chance that many patients may bypass primary care and seek more expensive outpatient care from hospitals [40]. In 2017, for example, on average, each Hubei resident made 5.77 outpatient visits: $60 \%$ in primary care facilities ( $75 \%$ shared by public facilities) and $40 \%$ in hospitals. (Table 1$)$. A study found that hospital consumption of antibiotics actually increased over the period from 2011 to 2014 in China [41]. The low antibiotic sales in primary care in Hubei may simply be a reflection of low consumer demands for primary care. It would be higher than the ESAC countries if the share of outpatient visits in primary care increased from the current level of $45 \%$ to a level aligned with the ESAC countries. This is likely to be the case given that previous studies revealed consistently high levels of antibiotic prescription in primary care in China, for example, $60 \%$ for upper respiratory infections [42]. We adjusted the absolute antibiotic sales figures in line with the market share of primary care facilities in outpatient visits. The results indicate that the sale of J01D in primary care in Hubei was higher than in most of the European countries.

However, the adjustment method used in this study has some limitations by itself. For example, antibiotic prescription rates vary across the primary care and hospital sectors due to differences in patient profiles. Over-the-counter (OTC) sales of antibiotics are another serious problem in China. A recent study revealed that more than $55 \%$ of community pharmacies in China sell antibiotics upon requests from their clients without requiring a prescription [43]. A global study showed that the weighted non-prescription use of antibiotics in China is around 36\%, compared with $6 \%$ in central Europe, $19 \%$ in southern Europe, and 3\% in northern Europe [44]. OTC sales of antibiotics would reduce the need of antibiotic prescriptions.

Accessibility to healthcare can also influence sales of antibiotics in healthcare facilities. China has achieved almost universal $(>96 \%)$ coverage of health insurance. Governmental subsidies to primary care institutions increased from $¥ 19$ billion (US\$2.8 billion) in 2008 to $¥ 140$ billion (\$20.3 billion) in 2015 [10]. The 2013 National Health Services Surveys show that over $85 \%$ of people in China visited a doctor when needed [45]. The universal health coverage index in China reached 76 according to the World Health Statics 2018, on par with the average level of European countries ( $>80$ in 14 European countries; 54-79 in 36 European countries).

In saying this, however, there is evidence that antibiotic sales are declining in primary care. This study revealed that total antibiotic sales in public primary care facilities in Hubei decreased more rapidly than the decline in patient visits, if any, over the study period. Several policy initiatives may have contributed to these results. Previous experience in China indicates that persuasive measures to reduce the overuse of antibiotics had only scant success. For example, the 2004 national guidelines on antibiotic use were criticised for its fragmented and incomplete approach [46]. Several restrictive measures imposed in the series of national essential medicines policies since 2009, such as the limited availability of antibiotics and zero-markup for sales of medicines in primary care, also had a limited effect on antibiotic prescribing practices [19-21]. This triggered stronger administrative interventions. 
The 2012 "Administrative Rules for the Clinical Use of Antibiotics" issued by the Hubei government appeared to work better according to findings of this study and others [47]. The dramatic decline in antibiotic sales in 2015, as shown in this study, also coincided with the "Management Measures on the Use of Essential Medicines in Medical Institutions in Hubei Province". For the first time, the Hubei government set a clear target to curb antibiotic use. In addition to persuasive guidelines, penalties applied for violating these administrative rules and measures. These included downgraded accreditation and service fee levels and the dismissal of managers. Medical workers involved may lose permission to prescribe antibiotics, or even have their medical registration revoked.

The quality use of antibiotics remains a concern in primary care in Hubei. This study found that most of the reduction in antibiotic sales occurred on two narrow-spectrum antibiotics, J01CE (beta-lactamase sensitive penicillins) and J01DB (first-generation cephalosporins), compared with limited reduction in broad-spectrum antibiotics such as J01DD (third-generation cephalosporins) and J01DC (second-generation cephalosporins). The sales of J01D (cephalosporins) in Hubei are significantly higher than those of most ESAC countries despite a lower volume of patient visits. Cephalosporins, together with broad-spectrum penicillins, are the most consumed antibiotics in the world, accounting for 55\% of the total antibiotics consumed in 2010. Between 2000 and 2010, cephalosporins experienced a large increase in sales globally [1]. The preference of clinicians in China to use cephalosporin (including $\beta$-lactamase inhibitor combination preparations) and fluoroquinolones is deemed a serious problem of professional incompetence [48]. This study also found that third-generation cephalosporins, mostly second-line treatment options, accounted for more than half of the total cephalosporin sales. Such a pattern was also observed in some countries in Eastern Europe and Central Asia [49]. Overuse of third-generation cephalosporins could induce the emergence and spread of drug-resistant strains of microbes, such as the vancomycin-resistant enterococci (VRE), the ESBLs-producing Klebsiella pneumoniae, and multi-drug resistant Gram-negative bacteria [50,51].

The overuse of parenteral antibiotic treatment is another global concern. The percentage of parenteral antibiotic sales (50-55\%) in Hubei as revealed in this study is much higher compared with European countries (ranging from $0.001 \%$ in Iceland to $6.75 \%$ in Russia) [52]. This result is consistent with findings of previous studies [53]. Although the sales of medicines generated a zero profit margin in primary care in China, a fee could be charged for administering injections or infusions [10]. Patient preference may further complicate the situation. In China, patients often perceive injections as being powerful, fast-acting, and longer lasting than oral pills, putting additional pressure on prescribers [54].

The national roadmap for health system development, Healthy China 2030, has highlighted the importance of primary care. With strong political will and commitment, the primary care sector in China is expected to be strengthened. Pilot trials in Shenzhen have demonstrated the steady growth in the share of patient visits in primary care when primary care providers serve as first point of contact in the integrated care delivery system [55]. In September 2017, the health ministry of China decided to extend this approach to the entire country. This will undoubtedly increase antibiotic sales in primary care. Increasing attention should be paid to the quality use of antibiotics in primary care, in particular, the potential excessive use of broad-spectrum antibiotics such as third-generation cephalosporins and the parenteral administration of medicines.

There are several limitations in this study. Data used in this study were drawn from procurement records, which do not directly reflect the actual use of medicines. We were also unable to evaluate the appropriateness of antibiotic prescribing practices. The HAMPS records did not capture the medicines in stock or expired or discarded medicines. Private primary care facilities were excluded in this study, although they accounted for $25 \%$ of patient visits in primary care [56]. The procurement records did not separate rural and urban sales, preventing us from exploring rural-urban differences. We were not able to perform risk adjustments in the benchmarking analysis due to the unavailability of relevant data. 


\section{Conclusions}

Using the procurement records, for the first time, we estimated antibiotic sales in public primary care facilities in Hubei over the period from 2012 to 2017. Public facilities shared 75\% of patient visits to primary care in Hubei, with the total sales of antibiotics ranging from 9.1 to 15.3 DID across the study period. There is a lack of robust evidence to show that antibiotic sales in primary care are lower in Hubei compared with other countries. Low sales of antibiotics may be a result of low needs for prescriptions and the low market share of primary care in outpatient visits. However, it is evident that the sales of antibiotics in public primary care facilities in Hubei are declining, in particular for narrow-spectrum antibiotics. However, the sales of broad-spectrum cephalosporins have remained high. In addition, third-generation cephalosporins accounted for more than half of the total cephalosporin sales. A high percentage (50-55\%) of parenteral antibiotic sales in Hubei were also found in this study. The preference of clinicians in China to use broad-spectrum and parenteral antibiotics deserves further study and policy attention.

Author Contributions: The co-authors had together contributed to the completion of this article. Specifically, it follows their individual contribution: conceptualization, Y.T. and X.Z.; methodology, Y.T. and Y.C.; formal analysis, Y.C. and K.Z.; resources, K.Z.; data curation, K.Z.; Writing-Original draft preparation, Y.T., C.L. and Y.C.; Writing-Review and editing, C.L. and X.Z.; supervision, Y.T. and X.Z.; project administration, Y.T.; funding acquisition, Y.T.

Funding: This work was supported by the National Natural Science Foundation of China [grant number 71704058].

Conflicts of Interest: The authors declare no conflict of interest.

\section{References}

1. Van Boeckel, T.P.; Gandra, S.; Ashok, A.; Caudron, Q.; Grenfell, B.T.; Levin, S.A.; Laxminarayan, R. Global antibiotic consumption 2000 to 2010: An analysis of national pharmaceutical sales data. Lancet Infect. Dis. 2014, 14, 742-750. [CrossRef]

2. Ghafur, A. Overconsumption of antibiotics. Lancet Infect. Dis. 2015, 15, 377. [CrossRef]

3. O'Neill, J. Antimicrobial Resistance: Tackling a Crisis for the Health and Wealth of Nations. Available online: https://amr-review.org/sites/default/files/AMR\%20Review\%20Paper\%20-\%20Tackling\%20a\%20crisis\% 20for\%20the\%20health\%20and\%20wealth\%20of\%20nations_1.pdf (accessed on 29 March 2019).

4. Sandle, T. The antibiotic crisis and the need for new forms of antibiotics. EC Microbiol. 2014, 1, 1-3.

5. Klein, E.Y.; Van Boeckel, T.P.; Martinez, E.M.; Pant, S.; Gandra, S.; Levin, S.A.; Goossens, H.; Laxminarayan, R. Global increase and geographic convergence in antibiotic consumption between 2000 and 2015. Proc. Natl. Acad. Sci. USA 2018, 115, E3463-E3470. [CrossRef] [PubMed]

6. The European Centre for Disease Prevention and Control (ECDC). Surveillance of Antimicrobial Consumption in Europe 2013-2014; The European Centre for Disease Prevention and Control (ECDC): Solna Municipality, Sweden, 2018.

7. Smieszek, T.; Pouwels, K.B.; Dolk, F.C.K.; Smith, D.R.M.; Hopkins, S.; Sharland, M.; Hay, A.D.; Moore, M.V.; Robotham, J.V. Potential for reducing inappropriate antibiotic prescribing in English primary care. J. Antimicrob. Chemother. 2018, 73, ii36-ii43. [CrossRef] [PubMed]

8. Fleming-Dutra, K.E.; Hersh, A.L.; Shapiro, D.J.; Bartoces, M.; Enns, E.A.; File, T.M., Jr.; Finkelstein, J.A.; Gerber, J.S.; Hyun, D.Y.; Linder, J.A.; et al. Prevalence of Inappropriate Antibiotic Prescriptions Among US Ambulatory Care Visits, 2010-2011. JAMA 2016, 315, 1864-1873. [CrossRef] [PubMed]

9. Wong, C.K.M.; Kung, K.; Au-Doung, P.L.W.; Ip, M.; Lee, N.; Fung, A.; Wong, S.Y.S. Antibiotic resistance rates and physician antibiotic prescription patterns of uncomplicated urinary tract infections in southern Chinese primary care. PLoS ONE 2017, 12, e0177266. [CrossRef] [PubMed]

10. Li, X.; Lu, J.; Hu, S.; Cheng, K.K.; De Maeseneer, J.; Meng, Q.; Mossialos, E.; Xu, D.R.; Yip, W.; Zhang, H.; et al. The primary health-care system in China. Lancet 2017, 390, 2584-2594. [CrossRef]

11. National Health Commission of the People's Republic of China National Health Service in China 2017. Available online: http://www.nhc.gov.cn/guihuaxxs/s10743/201806/44e3cdfe11fa4c7f928c879d435b6a18.shtml (accessed on 23 March 2019). 
12. Yin, X.; Song, F.; Gong, Y.; Tu, X.; Wang, Y.; Cao, S.; Liu, J.; Lu, Z. A systematic review of antibiotic utilization in China. J. Antimicrob. Chemother. 2013, 68, 2445-2452. [CrossRef]

13. Hay, A.D.; Thomas, M.; Montgomery, A.; Wetherell, M.; Lovering, A.; McNulty, C.; Lewis, D.; Carron, B.; Henderson, E.; MacGowan, A. The relationship between primary care antibiotic prescribing and bacterial resistance in adults in the community: A controlled observational study using individual patient data. J. Antimicrob. Chemother. 2005, 56, 146-153. [CrossRef]

14. Hillier, S.; Roberts, Z.; Dunstan, F.; Butler, C.; Howard, A.; Palmer, S. Prior antibiotics and risk of antibiotic-resistant community-acquired urinary tract infection: A case-control study. J. Antimicrob. Chemother. 2007, 60, 92-99. [CrossRef]

15. Samore, M.H.; Tonnerre, C.; Hannah, E.L.; Stoddard, G.J.; Borotkanics, R.J.; Haddadin, B.; Harbarth, S. Impact of Outpatient Antibiotic Use on Carriage of Ampicillin-Resistant Escherichia coli. Antimicrob. Agents Chemother. 2011, 55, 1135-1141. [CrossRef] [PubMed]

16. Costelloe, C.; Metcalfe, C.; Lovering, A.; Mant, D.; Hay, A.D. Effect of antibiotic prescribing in primary care on antimicrobial resistance in individual patients: Systematic review and meta-analysis. BMJ 2010, 340, c2096. [CrossRef] [PubMed]

17. Bryce, A.; Hay, A.D.; Lane, I.F.; Thornton, H.V.; Wootton, M.; Costelloe, C. Global prevalence of antibiotic resistance in paediatric urinary tract infections caused by Escherichia coli and association with routine use of antibiotics in primary care: Systematic review and meta-analysis. BMJ 2016, 352, i939. [CrossRef] [PubMed]

18. Yip, W.C.; Hsiao, W.C.; Chen, W.; Hu, S.; Ma, J.; Maynard, A. Early appraisal of China's huge and complex health-care reforms. Lancet 2012, 379, 833-842. [CrossRef]

19. Hu, S.; Tang, S.; Liu, Y.; Zhao, Y.; Escobar, M.L.; de Ferranti, D. Reform of how health care is paid for in China: Challenges and opportunities. Lancet 2008, 372, 1846-1853. [CrossRef]

20. Meng, Q.; Cheng, G.; Silver, L.; Sun, X.; Rehnberg, C.; Tomson, G. The impact of China's retail drug price control policy on hospital expenditures: A case study in two Shandong hospitals. Health Policy Plan. 2005, 20, 185-196. [CrossRef] [PubMed]

21. Han, S.; Liang, H.; Su, W.; Xue, Y.; Shi, L. Can price controls reduce pharmaceutical expenses? A case study of antibacterial expenditures in 12 Chinese hospitals from 1996 to 2005. Int. J. Health Serv. Plan. Adm. Eval. 2013, 43, 91-103. [CrossRef] [PubMed]

22. Zhang, W.; Liu, X.; Wang, Y.; Chen, Y.; Huang, M.; Fan, M.; Lu, M.; Huang, Y.; Wang, L.; Yao, K.; et al. Antibiotic use in pulmonology wards of Chinese children's hospitals: 2002-2006. J. Clin. Pharm. Ther. 2009, 34, 61-65. [CrossRef]

23. People's Medical Publishing House. Year Book of Health in the People's Republic of China; People's Medical Publishing House: Beijing, China, 2013.

24. Guan, X.; Liang, H.; Xue, Y.; Shi, L. An analysis of China's national essential medicines policy. J. Public Health Policy 2011, 32, 305-319. [CrossRef]

25. Chen, M.; Wang, L.; Chen, W.; Zhang, L.; Jiang, H.; Mao, W. Does economic incentive matter for rational use of medicine? China's experience from the essential medicines program. PharmacoEconomics 2014, 32, 245-255. [CrossRef] [PubMed]

26. Yang, L.; Liu, C.; Ferrier, J.A.; Zhou, W.; Zhang, X. The impact of the National Essential Medicines Policy on prescribing behaviours in primary care facilities in Hubei province of China. Health Policy Plan. 2013, 28, 750-760. [CrossRef] [PubMed]

27. Yi, H.; Miller, G.; Zhang, L.; Li, S.; Rozelle, S. Intended and unintended consequences of China's zero markup drug policy. Health Aff. 2015, 34, 1391-1398. [CrossRef] [PubMed]

28. Xiao, Y.; Li, L. Legislation of clinical antibiotic use in China. Lancet Infect. Dis. 2013, 13, 189-191. [CrossRef]

29. Tang, Y.; Liu, C.; Zhang, Z.; Zhang, X. Effects of prescription restrictive interventions on antibiotic procurement in primary care settings: A controlled interrupted time series study in China. Cost Eff. Resour. Alloc. 2018, 16, 1. [CrossRef] [PubMed]

30. The Measures for the Management of the Clinical Application of Antibacterial Drugs. Available online: http://www.moh.gov.cn/mohyzs/s3584/201205/54645.shtml (accessed on 12 July 2018).

31. Coenen, S.; Ferech, M.; Haaijer-Ruskamp, F.M.; Butler, C.C.; Vander Stichele, R.H.; Verheij, T.J.; Monnet, D.L.; Little, P.; Goossens, H. European Surveillance of Antimicrobial Consumption (ESAC): Quality indicators for outpatient antibiotic use in Europe. Qual. Saf. Health Care 2007, 16, 440-445. [CrossRef] [PubMed] 
32. Hubei Statistics Year Book 2016; China Statistics Press: Beijinng, China, 2016.

33. Department of Population and Employment Statistics National Burean of Statistics; Department of Planning and Finance Ministry of Human Resources ans Social Statistics. China Labour Statistical Yearbook 2017. Available online: http://data.cnki.net/yearbook/Single/N2018070151 (accessed on 29 March 2019).

34. National Health Commission of People's Republic of China. 2018 Year Book of Health Statistic in the People's Republic of China; China Union Medical University Press: Beijing, China, 2018.

35. Management Measures On Use of Essential Medicines in Medical Institutions in Hubei Province. Available online: http://www.chinaemed.com/Province/hubei/Docs/BaseMedFile/BaseMedFile/10674 (accessed on 1 April 2019).

36. ATC/DDD Index and Guidelines. Available online: http://www.whocc.no/atc_ddd_index/ (accessed on 14 April 2019).

37. The European Centre for Disease Prevention and Control (ECDC) Quality Indicators for Antibiotic Consumption in the Community. Available online: https:/ecdc.europa.eu/en/antimicrobial-consumption/ database/quality-indicators (accessed on 31 March 2019).

38. England, P.H. English Surveillance Programme for Antimicrobial Utilisation and Resistance (ESPAUR) Report 2018. Available online: https://assets.publishing.service.gov.uk/government/uploads/system/ uploads/attachment_data/file/759975/ESPAUR_2018_report.pdf?_ga=2.34148065.152362810.15668046941442484965.1566116176 (accessed on 22 August 2019).

39. Wu, D.; Lam, T.P.; Lam, K.F.; Zhou, X.D.; Sun, K.S. Public views towards community health and hospital-based outpatient services and their utilisation in Zhejiang, China: A mixed methods study. BMJ Open 2017, 7, e017611. [CrossRef]

40. Wu, D.; Lam, T.P.; Lam, K.F.; Zhou, X.D.; Sun, K.S. Health reforms in china: The public's choices for first-contact care in urban areas. Fam. Pract. 2017, 34, 194-200. [CrossRef]

41. Wushouer, H.; Tian, Y.; Guan, X.-D.; Han, S.; Shi, L.-W. Trends and patterns of antibiotic consumption in China's tertiary hospitals: Based on a 5 year surveillance with sales records, 2011-2015. PLoS ONE 2017, 12, e0190314. [CrossRef]

42. Zhang, Z.; Hu, Y.; Zou, G.; Lin, M.; Zeng, J.; Deng, S.; Zachariah, R.; Walley, J.; Tucker, J.D.; Wei, X. Antibiotic prescribing for upper respiratory infections among children in rural China: A cross-sectional study of outpatient prescriptions. Glob. Health Action 2017, 10, 1287334. [CrossRef]

43. Chang, J.; Ye, D.; Lv, B.; Jiang, M.; Zhu, S.; Yan, K.; Tian, Y.; Fang, Y. Sale of antibiotics without a prescription at community pharmacies in urban China: A multicentre cross-sectional survey. J. Antimicrob. Chemother. 2017, 72, 1235-1242. [CrossRef] [PubMed]

44. Morgan, D.J.; Okeke, I.N.; Laxminarayan, R.; Perencevich, E.N.; Weisenberg, S. Non-prescription antimicrobial use worldwide: A systematic review. Lancet Infect. Dis. 2011, 11, 692-701. [CrossRef]

45. Meng, Q.; Xu, L.; Zhang, Y.; Qian, J.; Cai, M.; Xin, Y.; Gao, J.; Xu, K.; Boerma, J.T.; Barber, S.L. Trends in access to health services and financial protection in China between 2003 and 2011: A cross-sectional study. Lancet 2012, 379, 805-814. [CrossRef]

46. Laxminarayan, R.; Duse, A.; Wattal, C.; Zaidi, A.K.; Wertheim, H.F.; Sumpradit, N.; Vlieghe, E.; Hara, G.L.; Gould, I.M.; Goossens, H.; et al. Antibiotic resistance-the need for global solutions. Lancet Infect. Dis. 2013, 13, 1057-1098. [CrossRef]

47. Zhang, W.; Shen, X.; Wang, Y.; Chen, Y.; Huang, M.; Zeng, Q.; Fan, M.; Bergman, U.; Yang, Y. Outpatient antibiotic use and assessment of antibiotic guidelines in Chinese children's hospitals. Eur. J. Clin. Pharmacol. 2008, 64, 821-828. [CrossRef] [PubMed]

48. Xiao, Y. Antimicrobial Stewardship in China: Systems, Actions and Future Strategies. Clin. Infect. Dis. 2018, 67, S135-S141. [CrossRef] [PubMed]

49. Robertson, J.; Iwamoto, K.; Hoxha, I.; Ghazaryan, L.; Abilova, V.; Cvijanovic, A.; Pyshnik, H.; Darakhvelidze, M.; Makalkina, L.; Jakupi, A.; et al. Antimicrobial Medicines Consumption in Eastern Europeand Central Asia-An Updated Cross-National Study and Assessment of QuantitativeMetrics for Policy Action. Front. Pharmacol. 2018, 9, 1156. [CrossRef] [PubMed]

50. Paterson, D.L. "Collateral damage" from cephalosporin or quinolone antibiotic therapy. Clin. Infect. Dis. 2004, 38, S341-S345. [CrossRef] [PubMed]

51. Du, B.; Chen, D.C.; Liu, D.W.; Long, Y.; Shi, Y.; Wang, H.; Rui, X.; Cui, N. Restriction of third-generation cephalosporin use decreases infection-related mortality. Crit. Care Med. 2003, 31, 1088-1093. [CrossRef] 
52. Coenen, S.; Muller, A.; Adriaenssens, N.; Vankerckhoven, V.; Hendrickx, E.; Goossens, H. European Surveillance of Antimicrobial Consumption (ESAC): Outpatient parenteral antibiotic treatment in Europe. J. Antimicrob. Chemother. 2014, 64, 200-205. [CrossRef] [PubMed]

53. Tang, Y.; Liu, C.; Zhang, X. Public reporting as a prescriptions quality improvement measure in primary care settings in China: Variations in effects associated with diagnoses. Sci. Rep. 2016, 6, 39361. [CrossRef] [PubMed]

54. Reynolds, L.; McKee, M. Serve the people or close the sale? Profit-driven overuse of injections and infusions in China's market-based healthcare system. Int. J. Health Plan. Manag. 2011, 26, 449-470. [CrossRef] [PubMed]

55. Wang, X.; Sun, X.; Birch, S.; Gong, F.; Valentijn, P.; Chen, L.; Zhang, Y.; Huang, Y.; Yang, H. People-centred integrated care in urban China. Bull. World Health Organ. 2018, 96, 843-852. [CrossRef] [PubMed]

56. Xu, J.; Wang, W.; Li, Y.; Zhang, J.; Pavlova, M.; Liu, H.; Yin, P.; Lu, Z. Analysis of factors influencing the outpatient workload at Chinese health centres. BMC Health Serv. Res. 2010, 10, 151. [CrossRef]

(C) 2019 by the authors. Licensee MDPI, Basel, Switzerland. This article is an open access article distributed under the terms and conditions of the Creative Commons Attribution (CC BY) license (http://creativecommons.org/licenses/by/4.0/). 